\title{
PERBEDAAN EFEKTIFITAS SENAM DISMINORE DAN AROMATERAPI TERHADAP PENURUNAN NYERI DISMINORE PADA MAHASISWA TINGKAT I JURUSAN KEBIDANAN POLTEKKES KEMENKES MATARAM
}

\author{
Oky Nila Kencana Sari ${ }^{1}$, Baiq Eka Putri Saudia ${ }^{2}$ \\ ${ }_{1}^{1}$ Program Studi Diploma IV Kebidanan,Jurusan Kebidanan Poltekkes Kemenkes Mataram \\ ${ }^{2}$ Program Studi Diploma IV Kebidanan,Jurusan Kebidanan Poltekkes Kemenkes Mataram
}

\begin{abstract}
Abstrak
Remaja putri yang telah memasuki masa pubertas akan mengalami siklus menstruasi. Terdapat kelainan atau gangguan ketika menstruasi berlangsung, hal tersebut diantaranya pre menstrual tension, mastodinia, mittelschmerz dan disminore. Ada tiga perlakuan managemen penanganan nyeri pada disminore primer yaitu dengan cara farmakologi, non farmakologi dan pembedahan Penanganan secara non farmakologis dapat dilakukan dengan cara : stimulasi syaraf (TENS / Transcutaneous Electrical Nerve Stimulation), acupuntur dan acupressure, dan self help terapy (kompres hangat, massage, latihan fisik atau olahraga, hipnoterapi, terapi musik, dan aromaterapi)

Penelitian ini bertujuan untuk mengetahui perbedaan efektifitas senam disminore dan aromaterapi terhadap penurunan nyeri disminore pada mahasiswa tingkat I jurusan kebidanan Poltekkes Mataram. Jenis penelitian ini adalah penelitian kuantitatif, dimana rancangan penelitian yang dipakai adalah Quasi Experimental Design dengan Nonequivalent Control Group Design yaitu dimana peneliti dapat mengontrol semua variabel luar yang mempengaruhi jalannya eksperimen. Dalam design ini, baik terdapat dua kelompok kontrol dan kelompok eksperimen dimana baik kelompok kontrol maupun kelompok eksperimen diberikan pre test, kemudian diberikan perlakuan dan terakhir diberikan post. Hasil uji Man-Whitney setelah diberikan Perlakuan antara kelompok kontrol dan perlakuan didapatkan nilai $\mathrm{p}$ adalah 0,004 . Hal ini menunjukkan nilai $\mathrm{p}<0,05$, maka dapat disimpulkan bahwa ada perbedaan skala nyeri disminore setelah diberikan Perlakuan antara kelompok kontrol dan kelompok eksperimen. dapat diartikan senam disminore lebih baik dalam menurunkan skala nyeri di bandingkan dengan terapi aromaterapi.
\end{abstract}

\section{Pendahuluan}

Remaja merupakan populasi terbesar di dunia yaitu 1,2 milyar. Setengah dari remaja tersebut terdapat di Asia dan seperempat atau 282 juta remaja terdapat di Asia Tenggara. Remaja putri yang telah memasuki masa pubertas akan mengalami siklus menstruasi.

Terdapat kelainan atau gangguan ketika menstruasi berlangsung, hal tersebut diantaranya pre menstrual tension (ketegangan sebelum menstruasi), mastodinia (mastalgia), 
yaitu terasa pembengkakan dan pembesaran payudara sebelum menstruasi, mittelschmerz (rasa nyeri saat ovulasi) dan disminore (rasa nyeri saat menstruasi) (Manuaba, et,al.,2009).

Menurut Sarwono (2011), dismenore adalah nyeri saat haid, biasanya dengan rasa kram dan terpusat di abdomen bawah. Keluhan nyeri haid dapat terjadi bervariasi mulai dari yang ringan sampai berat. Nyeri haid yang dimaksud adalah nyeri haid berat sampai menyebabkan perempuan tersebut datang berobat ke dokter atau mengobati dirinya sendiri dengan obat anti nyeri.

Dismenore ini terjadi pada 30-75\% wanita dan cenderung memerlukan pengobatan (Junizar, dkk, 2007). Ada tiga perlakuan managemen penanganan nyeri pada disminore primer yaitu dengan cara farmakologi, non farmakologi dan pembedahan (Dawood,2006). Pada penanganan secara farmakologi dapat dilakukan dengan cara pemberian obat-obatan, yaitu obat anti inflamasi non steroid (NSAIDs), Cyclooxygenase II Inhibitors (COX), pil kontrasepsi, glyceryl trinitrate, magnesium, calcium antagonists, vitamon B, vitamon $\mathrm{E}$, dan obat herbal. Penanganan secara non farmakologis dapat dilakukan dengan cara : stimulasi syaraf (TENS / Transcutaneous Electrical Nerve Stimulation), acupuntur dan acupressure, dan self help terapy (kompres hangat, massage, latihan fisik atau olahraga, hipnoterapi, terapi musik, dan aromaterapi). Penanganan melalui teknik bedah dilakukan dengan cara : Nerve Ablation, spinal manipulation (Dawood,2006).

Penanganan disminore selama ini lebih banyak kepada pemberian terapi farmakologik, seperti pemberian analgesik. Obat analgesikdapat menimbulkan efek toleransi, ketergantungan dan gejala putus obat (Hopfer \& Vallerand,200 ; Munaf 2008). Senam disminore fokus membantu peregangan seputar otot perut, panggul, dan pinggang, dengan senam tersebut dapat memberikan sensasi rileks yang berangsur-angsur dapat mengurangi nyeri ika dilakukan secara teratur (Badriyah dan Diyati,2004). Aromaterapi adalah cara penyembuhan dengan menggunakan konsentrasi minyak essential yang sangat aromatik yang diekstrasi dari tumbuhtumbuhan. Menghirup minyak aromaterapi dianggap sebagai cara penyembuhan yang paling langsung dan cepat.

Berdasarkan hasil wawancara yg dilakukan pada mahasiswa tingkat I kelas B Jurusan Kebidanan dari 36 jumlah mahasiswa didapatkan sebesar 30 orang selalu mengalami nyeri disminore saat haid, 4 orang mengatakan tidak pernah mengalami, dan 2 orang mengatakan tidak selalu mengalami nyeri disminore.Pada studi pendahuluan ini belum pernah ada yan melakukan senam disminore dan aromaterapi untuk menurunkan nyeri disminore. 


\section{METODE PENELITIAN}

Jenis penelitian ini adalah penelitian kuantitatif, dimana rancangan penelitian yang dipakai adalah Quasi Experimental Design dengan Nonequivalent Control Group Designyaitu dimana peneliti dapat mengontrol semua variabel luar yang mempengaruhi jalannya eksperimen. Dalam design ini, baik terdapat dua kelompok kontrol dan kelompok eksperimen dimana baik kelompok kontrol maupun kelompok eksperimen diberikan pre test, kemudian diberikan perlakuan dan terakhir diberikan post test.(Sugiyono,2010).

Pada kelompok kontrol diberikan aromaterapi selama kurang lebih 20 menit, sedangkan kelompok eksperimen diberikan pelatihan senam disminore sebanyak 3 kali yaitu 5-7 hari sebelum haid dengan durasi selama 30 menit (Saat H-1 dan Hari Pertama Menstruasi)

\section{a) Karakteristik Responden Berdasarkan Umur}

Tabel 1. Distribusi frekuensi berdasarkan umur

\begin{tabular}{ccc}
\hline Umur & $\begin{array}{c}\text { Frekuensi } \\
(\mathbf{n})\end{array}$ & $\begin{array}{c}\text { Persentase } \\
(\boldsymbol{\%})\end{array}$ \\
\hline $\begin{array}{c}\text { Remaja Akhir } \\
(17-25 \text { Tahun })\end{array}$ & 40 & 100 \\
\hline $\begin{array}{c}\text { Masa Dewasa Awal } \\
\text { (26-35 Tahun) }\end{array}$ & 0 & 0 \\
\hline Total & 40 & 100 \\
\hline
\end{tabular}

Berdasarkan tabel di atas dapat dilihat jumlah responden yaitu 40 dan semua responden termasuk kategori remaja akhir.

\section{b) Karakteristik Responden Berdasarkan Menarche}

Tabel 5.2 Distribusi frekuensi berdasarkan Menarche

\begin{tabular}{lccl}
\hline No & Umur & Frekuensi (n) & $\begin{array}{c}\text { Persentase } \\
(\boldsymbol{\%})\end{array}$ \\
\hline 1 & 11 & 7 & 17.5 \\
\hline 2 & 12 & 13 & 32.5 \\
\hline 3 & 13 & 10 & 25.0 \\
\hline 4 & 14 & 6 & 15.0 \\
\hline 5 & 15 & 4 & 10.0 \\
\hline & Total & 40 & 100.0
\end{tabular}

Dari tabel distribusi frekuensi di atas dapat dilihat jumlah terbanyak yang mengalamimenarche pada usia 12 tahun sebanyak 13 responden (32.5\%) sedangkan yang terkecil yaitu pada usia 15 tahun sebanyak 4 responden (10.0\%) 


\section{c) Karakteristik Responden Berdasarkan Siklus Haid (28-30 hari)}

Tabel 5.3 Distribusi frekuensi berdasarkan Siklus Haid

\begin{tabular}{cccc}
\hline No & SiklusHaid & Frekuensi (n) & Persentase (\%) \\
\hline 1 & Teratur & 32 & 80 \\
\hline 2 & TidakTeratur & 8 & 20 \\
\hline & Total & 40 & 100
\end{tabular}

Dari tabel distribusi di atas dapat dilihat jumlah siklus haid terbanyak pada kategori teratur yaitu sebanyak 32 responden $(80 \%)$ dan terkecil yaitu pada kategori siklus haid tidak teratur sebanyak $8(20 \%)$.

Tabel 5.4Rerata Nilai Skala Nyeri Pada Kelompok Eksperimen dan Kelompok Kontrol sebelum dan sesudah diberikan Senam Disminore dan Aromaterapi.

\begin{tabular}{clcccc}
\hline Variabel & Kelompok & Mean & Median & SD & Min-maks \\
\hline \multirow{2}{*}{ SkalaNyeri } & Kontrol & & & & \\
& Sebelum & 3.60 & 4.00 & 0.670 & $3-5$ \\
& Sesudah & 3.85 & 4.00 & 0.882 & $2-5$ \\
\cline { 2 - 6 } & Perlakuan & & & & \\
& Sebelum & 3.70 & 4.00 & 0.732 & $3-5$ \\
& Sesudah & 1.95 & 2.00 & 0.887 & $1-4$ \\
\hline
\end{tabular}

Hasil analisis pada tabel 5.1 menunjukkan rerata nilai skala nyeri pada kelompok kontrol sebelum di berikan Perlakuan yaitu 3.60 dengan nilai skala nyeri terendah 3 dan tertinggi 5, sedangkan setelah diberikan perlakuan nilai rerata pada kelompok kontrol yaitu 3.85 dengan nilai terendah yaitu 2 dan tertinggi 5. Hasil analisis Skala nyeri pada kelompok eksperimen sebelum di berikan perlakuan nilai rata-rata yaitu 3.70 dengan nilai terendah 3 dan tertinggi 5, sedangkan setelah di berikan perlakuan nilai rerata skala nyeri pada kelompok eksperimen turun menjadi 1.95 dengan nilai terendah 1 dan tertinggi 4.

Tabel 5.5 Hasil Uji Normalitas Data Pada Variabel Skala Nyeri Sebelum dan Sesudah Dilakukan Intervensi Pada Kelompok Perlakuan dan Kontrol.

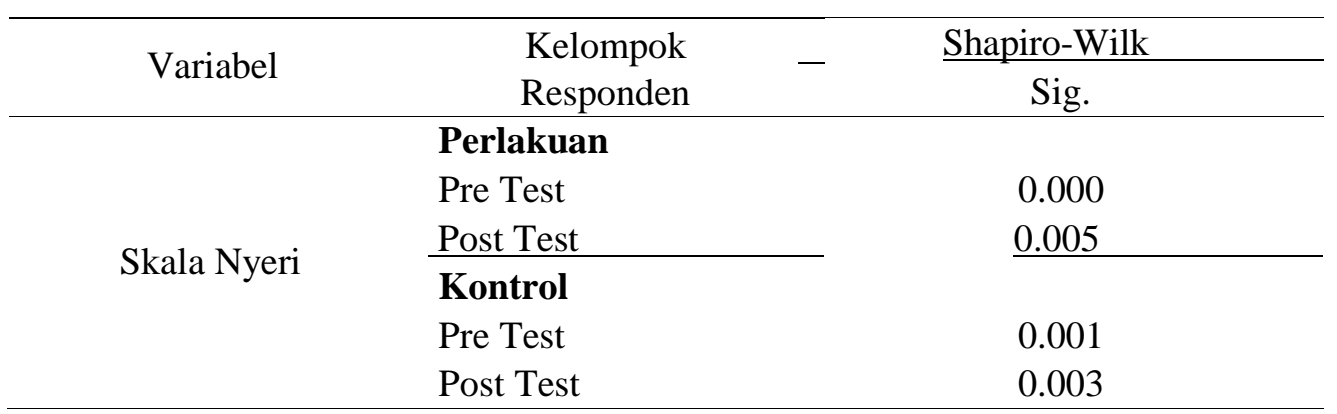

Hasil uji normalitas menunjukkan seluruh data bernilai sig $<0.05$ sehingga data tidak 
berdistribusi normal. Uji yang digunakan dalam penelitian ini untuk mengetahui perbedaan hasil data sebelumdan sesudah diberikan perlakuan pada kelompok kontrol dan eksperimen menggunakan Uji Wilcoxon, sedangkan untuk mengetahui perbedaan tingkat nyeri antara kelompok kontrol dan kelompok eksperimen pada data setelah diberikan perlakuan menggunakan Uji Man Whitney

Tabel 5.6 Efektivitas Senam Disminore dan aromaterapi dalam Mengatasi nyeri disminore pada mahasiswa tingkat I Jurusan Kebidanan di Poltekkes Kemenkes Mataram Sebelum dan Sesudah Diberikan Intervensi Pada Kelompok Kontrol dan Kelompok Eksperimen

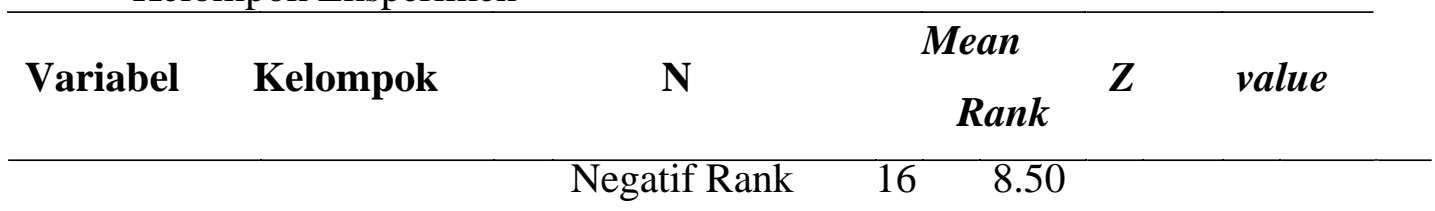

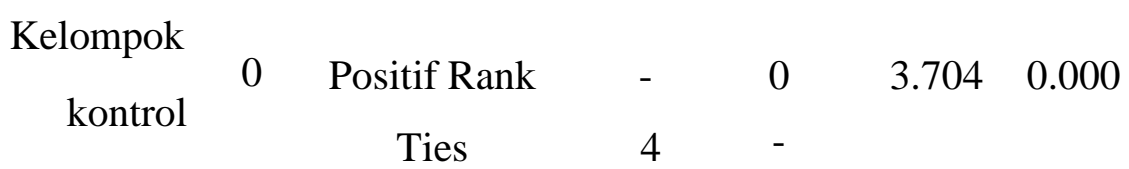

Skala Nyeri

\begin{tabular}{|c|c|c|c|c|c|}
\hline & Negatif Rank & 20 & 10.50 & & \\
\hline eksperimen 0 & Positif Rank & - & 0 & 3.985 & 0.000 \\
\hline
\end{tabular}

Ties

Hasil Uji Wilcoxon pada kelompok kontrol sebelum dan sesudah diberikan intervensi didapatkan nilai $\mathrm{p}$ ( $p$ value) adalah 0,218 . Hal ini menunjukkan nilai $\mathrm{p}<0.05$, maka dapat disimpulkan ada pengaruh pada tingkat nyeri pada kelompok kontrol sebelum dan sesudah diberikan perlakuan. Pada kelompok eksperimen hasil sebelum dan sesudah

Tabel 5.7 Perbedaan Efektifitas Skala nyeri disminore Sebelum dan Sesudah Diberikan senam disminore dan aromaterapi Antara Kelompok Kontrol dan Kelompok Perlakuan

\begin{tabular}{cccccc}
\hline Variabel & Kelompok & N & Mean Rank & $Z$ & p value \\
\hline \multirow{2}{*}{ Skala Nyeri } & Kelompok kontrol & 20 & 15.70 & & \multirow{2}{*}{ Kelo } \\
& Kelompok perlakuan & 20 & 25.30 & -2.845 & 0.004
\end{tabular}

Hasil uji Man-Whitney setelah diberikan Perlakuan antara kelompok kontrol dan perlakuan didapatkan nilai $\mathrm{p}$ adalah 0,004 . Hal ini menunjukkan nilai $\mathrm{p}<0,05$, maka dapat disimpulkan bahwa ada perbedaan skala nyeri disminore setelah diberikan Perlakuan antara kelompok kontrol dan kelompok eksperimrn. Dari nilai mean rank, dapat dilihat 
nilai rank pada kelompok eksperimen 25.30 lebih besar dari kelompok kontrol 15.70, jadi dapat diartikan senam disminore lebih baik dalam menurunkan skala nyeri di bandingkan dengan terapi aromaterapi.

\section{PEMBAHASAN}

Menurut Sarwono (2011), dismenore adalah nyeri saat haid, biasanya dengan rasa kram dan terpusat di abdomen bawah. Sedangkan menurut Karim (2013), dismenore merujuk pada keseluruhan gejala-gejala nyeri yang timbul ketika menstruasi, yang dapat dibedakan menjadi dismenore primer dan sekunder. Disminore yang sering terjadi pada remaja adalah disminore primer.

Hasil penelitian menunjukkan bahwa nilai $\mathrm{p}<0.05$, maka dapat disimpulkan ada pengaruh pada tingkat nyeri pada kelompok kontrol sebelum dan sesudah diberikan perlakuan. Pada kelompok eksperimen hasil sebelum dan sesudah diberikan intervensi didapatkan nilai $\mathrm{p}$ adalah 0,000 . Hal ini menunjukkan nilai $\mathrm{p}<0.05$, yang berarti ada pengaruh senam disminore dalam menurunkan skala nyeri pada kelompok eksperimen sebelum dan sesudah diberikan perlakuan.

Perubahan tingkat nyeri disminore pada responden setelah dilakukan latihan senam disminore sesuai dengan teori menurut Sugani dan Priandani 2010, yang mengatakan bahwa latihan tubuh atau senam yang dilakukan saat disminore dapat menolong otot-otot yang mengalami ketegangan untuk menjadi relaks. Otot-otot uterus yang mengalami ketegangan saat disminore ketika diberikan latihan tubuh atau senam yang berokus pada pada bagian panggul, menyebabkan otot-otot uterus yang tegang mengalami relaksasi dan nyeri pun berangsur-angsur berkurang. Saat melakukan senam seseorang menjadi lebih nyaman, gembira, dan dapat melancarkan pengiriman oksigen ke otot.

Sesuai dengan teori yang dikemukakan oleh Najmi (2011), aromaterapi dapat menurunkan tingkat nyeri pada sesorang yang mengalami disminore, sebab aromaterapi dapat memberikan efek stimulasi, memberikan sensasi yang menenangkan diri, otak, keseimbangan, stress yang dirasakan, relaksasi pada pikiran, dan fisik pada tubuh sehingga efek inilah yang dapat menurunkan nyeri pada sesorang. Jika pikiran, terasa tenang dan rileks maka akan tercipta suasana yang nyaman dan nyeri haid pun bisa berkurang.

Hasil uji Man-Whitney setelah diberikan Perlakuan antara kelompok kontrol dan perlakuan didapatkan nilai $\mathrm{p}$ adalah 0,004 . Hal ini menunjukkan nilai $\mathrm{p}<0,05$, maka dapat disimpulkan bahwa ada perbedaan skala nyeri disminore setelah diberikan Perlakuan antara kelompok kontrol dan perlakuan. Dari nilai mean rank, dapat dilihat nilai rank pada kelompok 
perlakuan 25.30 lebih besar dari kelompok kontrol, jadi dapat diartikan senam disminore lebih baik dalam menurunkan skala nyeri di bandingkan dengan terapi aromaterapi.

Senam disminore fokus membantu peregangan seputar otot perut, panggul, dan pinggang, dengan senam tersebut dapat memberikan sensasi rileks yang berangsur- angsur dapat mengurangi nyeri ika dilakukan secara teratur (Badriyah dan Diyati,2004). Penelitian yang dilakukan oleh oleh Puji (2009) menyatakan bahwa senam disminore ternyata efektif menurunkan nyeri haid (disminore) pada remaja sebesar 73,33\% dari nyeri sedang ke nyeri ringan, sedangkan sebanyak $26,67 \&$ mengalami penurunan nyeri dari nyeri berat ke nyeri sedang.

\section{SIMPULAN}

Berdasarkan pemaparan hasil penelitian yang telah dilakukan pada bab sebelumnya, maka dapat ditarik kesimpulan yaitu sebagai berikut :

1. Responden yang mengalami nyeri disminore sebelum dilakukan senam disminore mengalami perununan signifikan terhadap tingkat rasa nyeri yang dialami

2. Responden yang mengalami rasa nyeri disminore sebelum diberikan aromaterapi tidak mengalami penurunan tingkat rasa nyeri yang dialami.

3. Hasil uji data yang dilakukan menunjukkan bahwa pemberian senam dan aromaterapi pada penderita nyeri disminore efektif untuk menurunkan rasa nyeri disminore. Artinya senam disminore dan aromaterapi berpengaruh terhadap penurunan tingkat rasa nyeri disminore dan menunjukkan bahwa senam disminore lebih efektif menurunkan nyeri disminore dibandingkan dengan aromaterapi.

\section{SARAN}

Ketika melakukan penelitian, ditemukan beberapa hal yang selayaknya mendapat masukan perbaikan dari beberapa hal sebagai berikut :

1. Bagi Responden Remaja Puri

Penelitian ini diharapkan dapat dijadikan referensi bagi remaja putri dalam mengatasi disminore selain menggunakan obat-obatan yaitu dengan terapi non farmakoogis seperti senam dan aromaterapi.

2. Bagi Peneliti Selanjutnya

Bagi peneliti selanjutnya diharapkan dapat mengembangkan penelitian ini lebih khusus lagi seperti jenis aromaterapi yang digunakan lebih spesiik lagi. 


\section{DAFTAR PUSTAKA}

1. Arikunto, S. 2006. Prosedur Penelitian Suatu Pendekatan Praktik. Jakarta : Rineka Cipta

2. Agustiani, H. 2006. Psikologi Perkembangan : Pendekatan Ekologi Kaitannya Dengan KonsepDiri Pada Remaja . Replika Aditama

3. Badan Pusat Statistik. 2014. Profil Pemuda Indonesia. Jakarta

4. Badriyah dan Diyati. 2004. Be SmartGirl : Petunjuk Islami Kesehatan Reproduksi Bagi Remaja. Jakarta: Gema Insani

5. Bobak, Lowdermik, Jansen. 2004. Buku Ajar Keperawatan Maternitas. Jakarta :EGC

6. Bare, BG \& Smeltzer, S.C. 2001. Buku Ajar Keperawatan Medikal Bedah. Jakarta : EGC

7. Brooker . 2008. Ensiklopedia Keperawatan. Jakarta: EGC

8. Calis, Karim Anton. 2011. Dysmenorrhea, dari http: /emedicine.medscape.com/article/253812- overview. : (Diakses pada tanggal 10 Januari 2018)

9. Dawood, M.Y. 2006. Primary dysmenorrhea Advances in Pathogenesis and Management. Journal Obstetric and Gynekology Vol 108, No. 2, August, Published by Lippincott Wiliiams \& Wilkins. ISSN: 0029-7844/0

10. Harry. 2007. Mekanisme Endorphine Dalam Tubuh. Jakarta. EGC

11. Hurlock. 2002. Psikologi Perkembangan. Jakarta : Erlangga

12. Hillard, adams, and Datch, Helen Ron. 2006. Menstrual Disorder In The Collage Age Female. Journal Pediatric Clinic North America. 52 (1) : 189-197

13. Joseph, H.K dan Nugroho, M. 2010. Catatan Kuliah Ginekologi dan Obstetri (Obgyn). Yogyakarta : Nuha Medika

14. Manuaba, Ida Ayu Chandranita,et,al. 2009. Ilmu Kebidanan, Penyakit Kandungan dan KB Untuk Pendidian Bidan Edisi 2. Jakarta : Buku Kedokteran EGC

15. Karim Anton, C., \& Michael R, R Dysmenorrhea. Medscape Refference. 2013

16. Kemenkes RI tahun 2011. Profil Kesehatan Indonesia 2010. Jakarta

17. Kingston. 2009. Mengatasi Nyeri Haid. Jakarta : Ancan

18. Notoadmojo, S. 2005. Metodologi Penelitian Kesehatan. Jakarta : Rineka Cipta

19. Primadiati, Rachmi. 2002. Aromaterapi Perawatan Alami Untuk Sehat dan Cantik. Jakarta : Gramedia Pustaka Ilmu

20. Potter, A. 2005. Fundamental Keperawatan. Jakarta: EGC

21. Potter, A \& Perry, A.G. 2006. Buku Ajar Fundamental Keperawatan : Konsep, Proses, dan Praktik, edisi Volume 2. Jakarta : EGC

22. Price, S.A. \& Wilson, L.M. 2005. Patofisiologi : Konsep Klinis Proses-Proses Penyakit, Edisi 6, Volume 1. Jakarta : EGC

23. Proverawati, A \& Maisaroh, S. 2009. Menarche Menstruasi Pertama Penuh Makna. Yogyakarta : Nuhamed

24. Primadiati, Rachmi. 2002. Aromaterapi Perawatan Alami Untuk Sehat dan Cantik. Jakarta : Gramedia Pustaka Utama.

25. Rafika, Renata. 2013. "Rancangan Ulang Kemasan Viko aromaterapi” Desain Komunikasi Visual Bina Nusantara.

26. Rumini, Sri dan Siti Sundari. 2004. Perkembangan Anak dan Remaja. Jakarta : PT Rineka Cipta

27. Ramaiah. 2006. Mengatasi Gangguan Menstruasi. Yogyakarta : Diglosia Medika

28. Sarwono, Prawirohardjo. 2011. Ilmu Kebidanan. Edisi Tiga, Yayasan Bina Pustaka. SP: Jakarta

29. Simajuntak, Pandapotan. 2008. Gangguan Haid dan Siklusnya. Dalam : Prawirohardjo, Sarono, Winkjosastro, Hanifa, edisi 2. Ilmu Kandungan. Jakarta : Bina Pustaka Sarwono Prawirohardjo,

30. Sastrawinata. 2008. Ilmu Kesehatan Reproduksi : Obtetri Patologi. Jakarta : EGC Smeltzer C, Suzanne. 2002. Buku Ajar Keperawatan Medikal Bedah. Jakarta : EGC Synder, et. al., 2012. Fundamental of Nursing : Concepts, Process, and Practise( 9 th ed)

31. Sugiyono. 2008 Metode Penelitian Kuantitatif Kualitatif dan R\&D. Bandung : Alabeta

32. Wirakusumah, Emma S. 2004. Tip dan Solusi Agar Tetap Sehat, Cantik Dan Bahagia Di Masa Menopause. Jakarta : PT Gramedia Pustaka Utamarta

33. Winkjosastro, G.H. 2008. Buku Acuan Persalinan Normal. $5^{\text {th }}$ ed. Jakarta : JNP-KR 